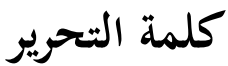

\section{الكليات الأساسية للشريعة الإسلامية}

\section{هيئة التحرير}

تنطلق بحوث هذا العدد من المحلة من فكرة الكُليات في العلوم الإسلامية، أو تحتكم إليها، وذلك بالمعنى العام للكليات بوصفها قواعد كبرى ومقاصد عامة. وهو توجُّهُ مهـمُّم

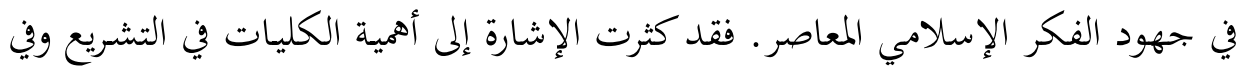
لغة الفقهاء والدعاة والسياسيين، وذلك في سياق البحث عن الجوامع المشتركة بين فئات الأمة، بل وبين الأمة وغيرها من الأمم.

وليس من السهل على قارئ هذه البحوث ممن يتابع كتابات شيخنا الدكتور أحمد

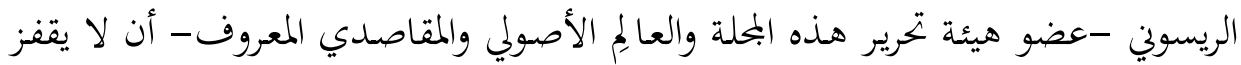

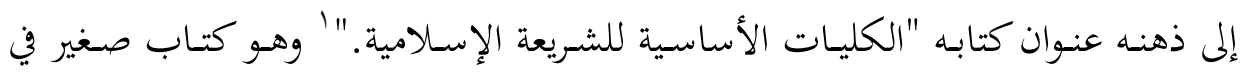

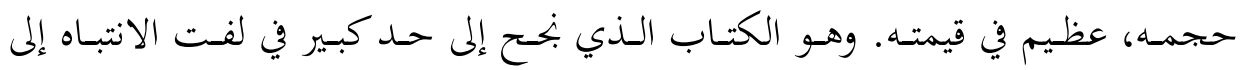

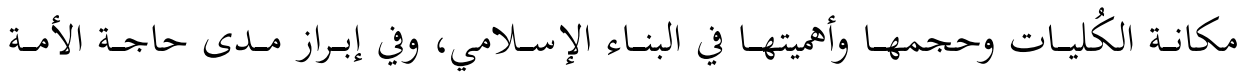

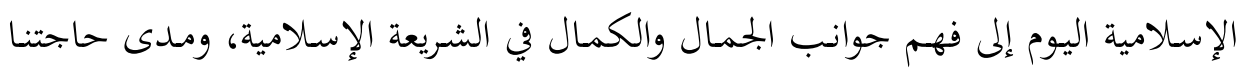

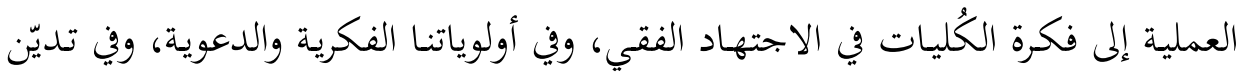

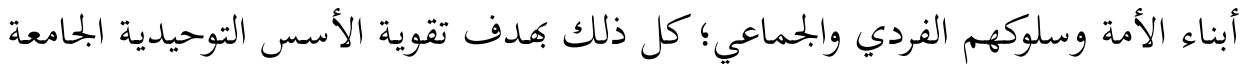

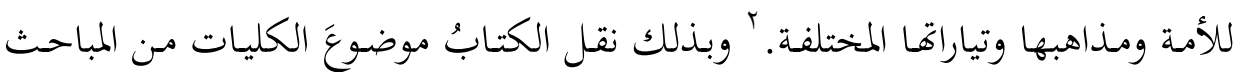

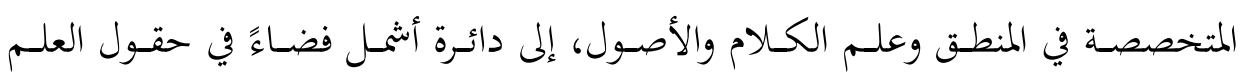
والفكر والثقافة، وجعَلَه أقربَ منالاً وأيسر تناوعلاً.

وقد يكون من المفيد أن نستمثر هذه المساحة الضيقة في التعريف الموجز بالكتاب،

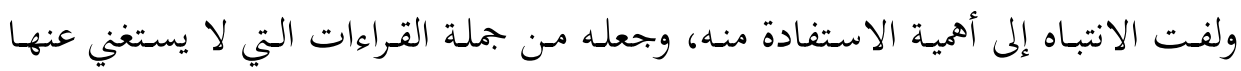
' الريسوني، أحمد. الكليات الأساسية للشريعة الإسلامية، طبعة منقحة ومزيدة، الرباط: حركة التوحيد والإصلاح، 
الباحثون وطلبة العلم، سواءً في سياق العلم الشرعي، أو البناء الفكري، أو حتى الثقافة العامة.

يتكون الكتاب من ثلاثة فصول وفق العناوين الآتية: الكليات التشريعية ومكانتها في القرآن والكتب السابقة، كليات القرآن: تصنيف وبيان، القضايا التشريعية: قضايا أصولية فقهية. وقد بيَّن المؤلف أن الكليات في شريعة الإسلام ثابتة ومستقرة، وهي كذلك في وني

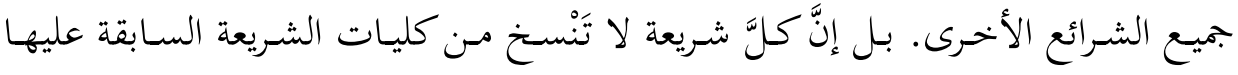

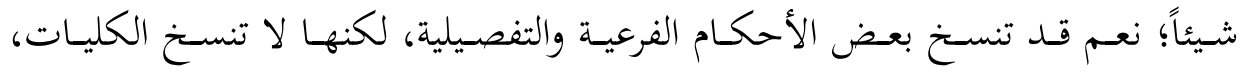
بوصفها عناصر في الدين الواحد الذي جاء به جميع الأنبياء. واختـار الريسوني القرآن الكريم -وليس شيئاً آخر - أن يكون مرجعيََّّهَ في الحـديث

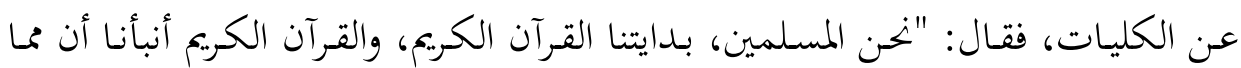
فيه: آيات محكمات هـن الأمهات، وهـن بداية البداية. فعلينا أن نركز أنظارنا، أبصارنا

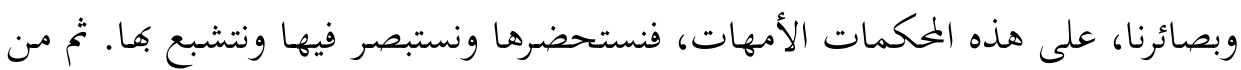
خلالما نتعامل مع سائر آي القرآن الكريم. ومن خلالها ومن خلال القرآن الكريم، نتعامل

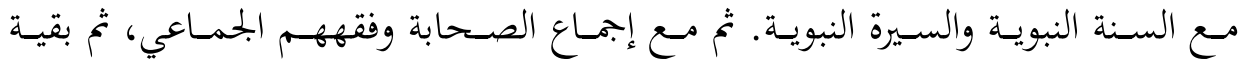

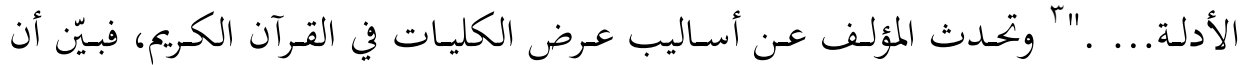
القرآن الكريم ليس مدونة قانونية بالمعنى المعاصر، ولكنه كتاب هداية عامة للإنسان، وله

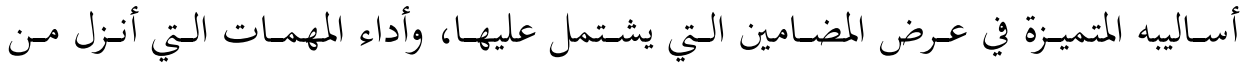
أجلها.

وقد ناقش المؤلف آراء بعض العلماء ممن قالوا بنسخ آيات من القرآن تختص ببعض

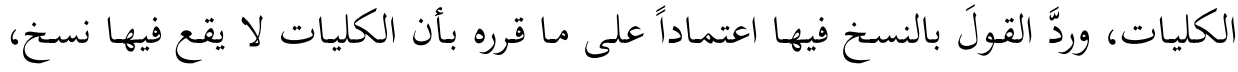

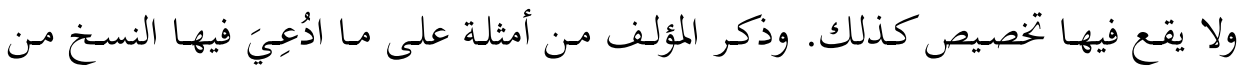

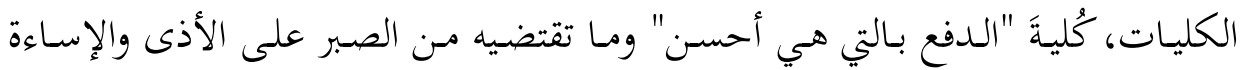

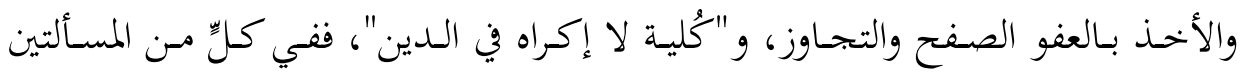


آيات "عحممات" "كليات" باقية على إحكامها وعمومها وغير قابلة للنسخ؛ لأهـا من القواعد الإلهية والسنن الربانية في السلوك المرغوب في بحالات الاجتماع البشري.

الكليـات الأساسـية للشـريعة هـي مقدمـة الشـريعة وأساسـها المتـين. فهي "مقدمـة

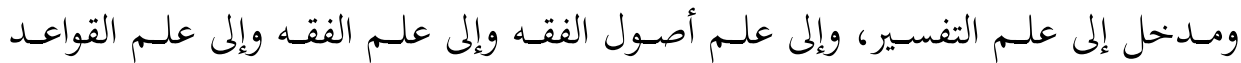

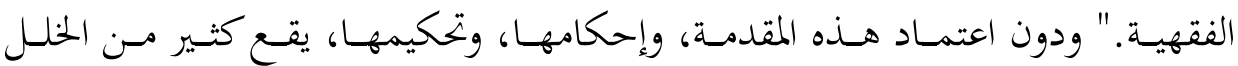

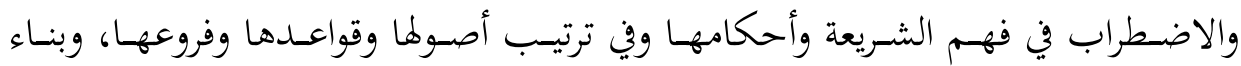

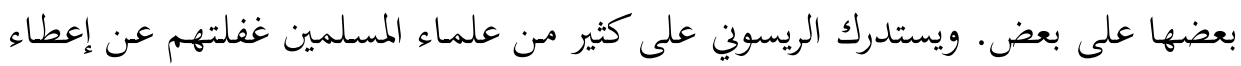

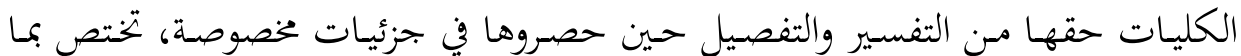
توسعوا في شرحه وتفصيله من آيات الأحكام، وعدم الاهتمام بما لا يقع بصورة مباشرة في تلك الجزئيات المخصوصة.

ويوضح الريسوني مفهوم الكليات الأساسية، فيؤكد أنَّ ما يعنيه هو: "المعاني والمبادئ

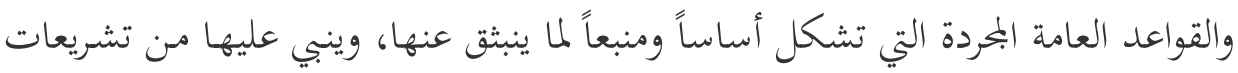

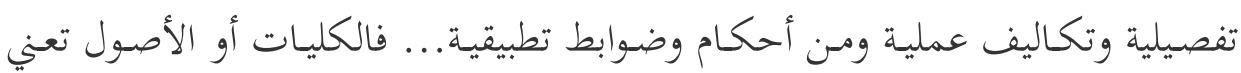

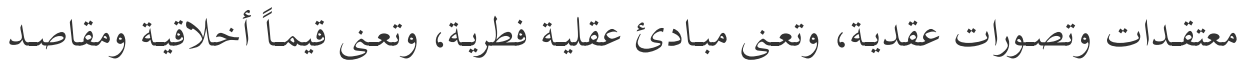

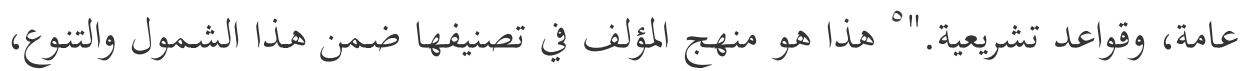

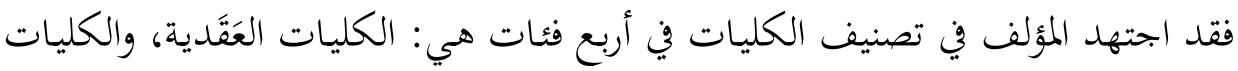

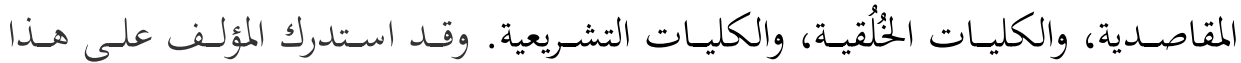

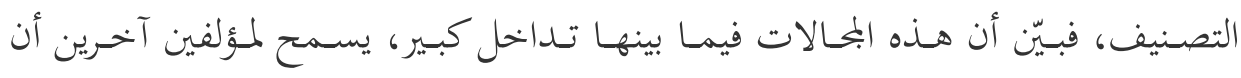

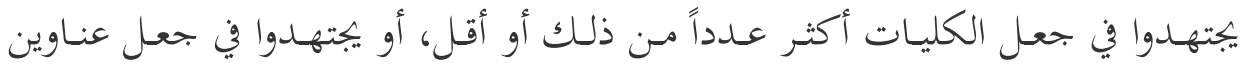
الكليات عناوين أخرى قد تكون عنده عناوين لبعض الجزئيات.

وعلى ذلك يكـون الغرض مـن الكتـاب: "تققيـق هـدف ضـروري واحـد هـو إبـراز

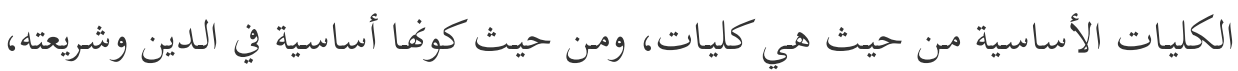

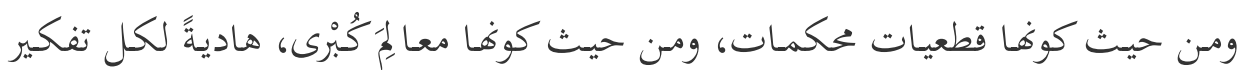

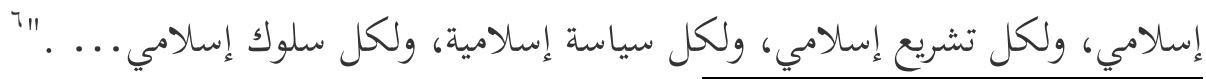

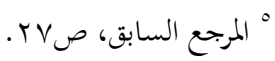
"المرجع السابق، صץ صل ـا. 
تم يتحدث المؤلف عن كليات أكبر وأعم من الكليات التي ذكر أمثلة عليها ضمن

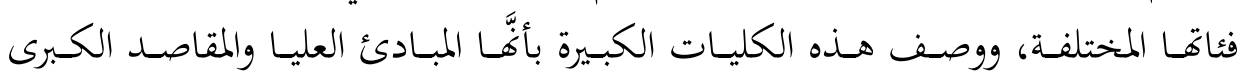

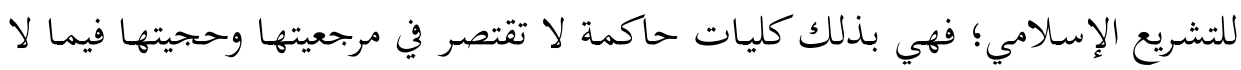

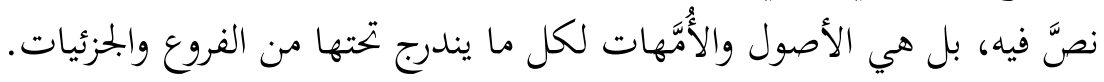
ويفـرد المؤلف مبحثاً عـن الكليـات المشتركة بـين الكتـب المنزلة، ويبـين أهـا مختلفـة

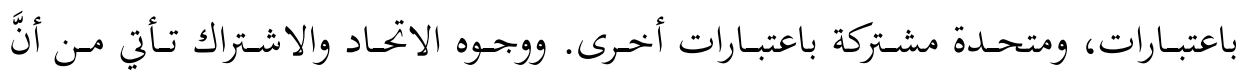

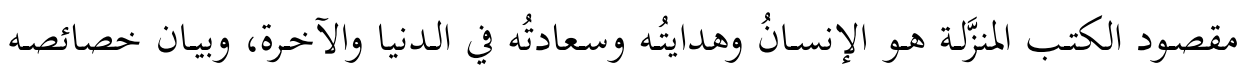

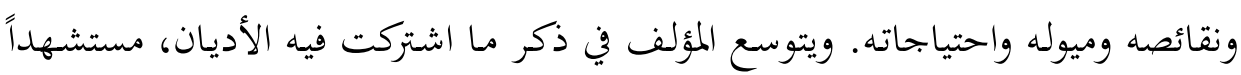

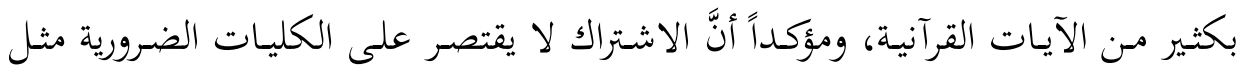

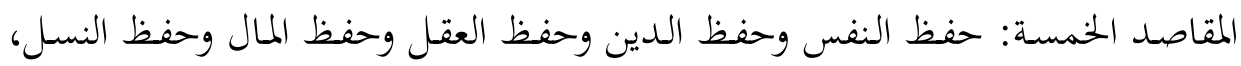

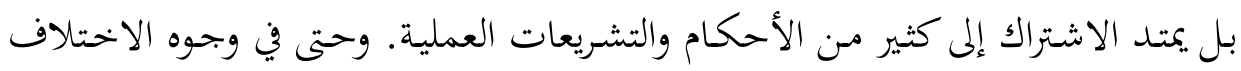

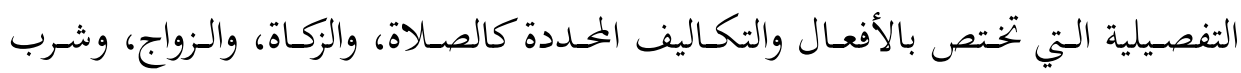

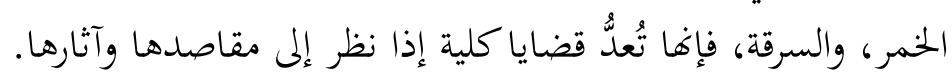
نكتفـي بهـا القـدر، فالمقصـود بهـذه الإشـارات هـو التنويـه بأهمية الكتـاب، وضـرورة إشاعته، والاستفادة مما فيه، وإدارة حلقات البحث والمناقشة حوله.

أمـا بحوث هذا العدد فإنها تحوم حول موضوع الكليات بشكل مباشر في بعضها

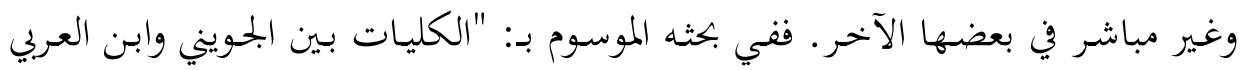

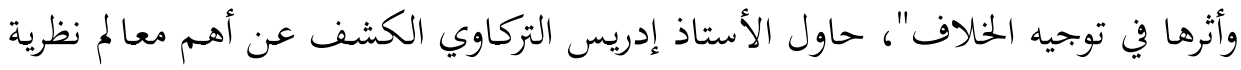

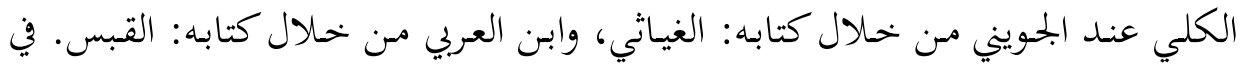
مسعى لتبيّن حقيقة الكلي المفهومية، وبيان وظيفته المنهجية. أما الدكتور أيمن الدباغ، فقد هدف من بحثه المعنون بـ: "حرية الإنسان في السياسة

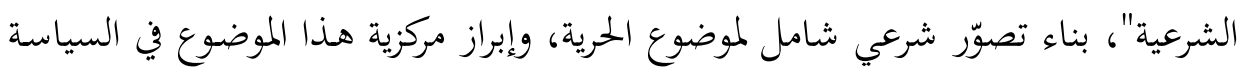
الشرعية، والكشف عن القواعد التي تحكم موضوع الحرية في السياسة الشرعية. وكشف الباحثان الدكتور عبد المجيد الصلاحين والدكتور هايل عبد الحفيظ عن أهمية

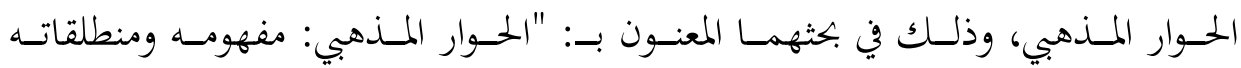




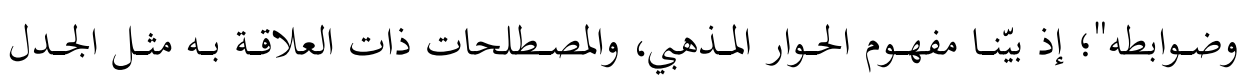
والمناظرة، والأسس التي يبنى عليها الحوار، والضوابط التي تعين في تحقيق الغرض منه. أمـا بحـث الـدكتوره تمـام العسـاف الموسـوم بــ: "أثتر المصـلحة في تقريـر الأحكـام الشرعية"، فقد ركّز على ضرورة فهم المصلحة الشرعية عند التطرق إلى علاقتنا بالآخر؛

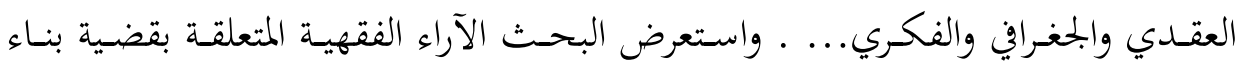
معابد غير المسلمين في الديار الإسلامية، والأدلة النقلية والعقلية للمعارضين والمؤيدين.

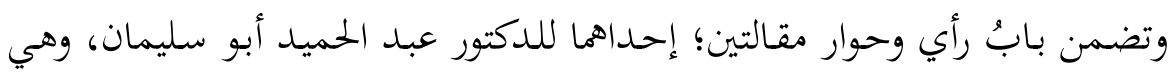

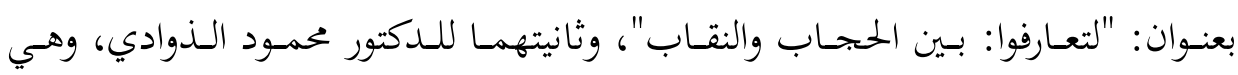
بعنوان: "وعلّم آدم الأسماء كلها في ميزان نظرية الرموز الثقافية". واحتوى العددُ قراءتين: قراءة لكتاب "مسؤولية التأويل" لمؤلفه الدكتور مصطفى

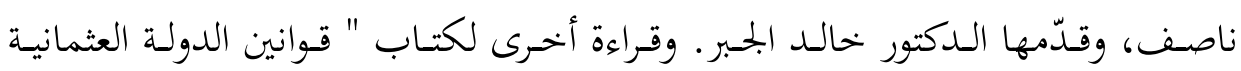

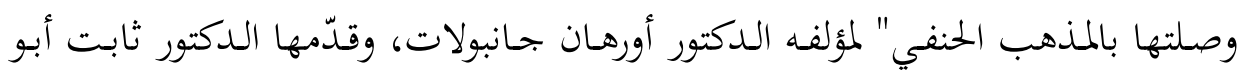
الحاج.

وفي العـد حلقـة جديـدة مـن عـروض مختصـرة، تكشف عـن أحسدث الإصـدارات الفكرية والمعرفية المتصلة بأبحاث العدد. سائلين المولى السداد والرشاد.. والحمد لله رب العالمين 